\title{
PENGARUH GAME HIDE A WORD TERHADAP KEMAMPUAN BERBICARA BAHASA INGGRIS SISWA
}

\author{
JUNI HARTIWI \\ ABA Dian Cipta Cendikia \\ e-mail: juni_marvel@yahoo.com
}

\begin{abstract}
ABSTRAK
Dalam pembelajaran yang dilakukan oleh guru untuk membantu siswa agar lebih terampil menggunakan bahasa yang sedang dipelajari, sering kali game menjadi salah satu pilihannya. Ada ratusan game yang bisa digunakan dalam proses belajar mengajar. Secara alamiah, kebanyakan siswa menyukai game dalam dunia mereka, salah satunya adalah Game Hide a Word. Penelitian ini bertujuan untuk mencari tahu apakah Game Hide a Word dapat meningkatkan kemampuan berbicara bahasa Inggris mahasiswa. Subjek penelitian ini adalah mahasiswa D3MI2 AMIK Dian Cipta Cendikia yang berjumlah 38 orang. Hasil penelitian menunjukkan bahwa Game Hide a Word berpengaruh yang positif dan signifikan terhadap kemampuan berbicara mahasiswa, terutama pada komponen accuracy dan fluency. Yang mencakup ketepatan kalimat yang dibuat oleh mahasiswa dan kelancaran mahasiswa dalam menyampaikan kalimat secara lisan.
\end{abstract}

Kata Kunci: kemampuan bicara, game, hide a word

\section{PENDAHULUAN}

Sebagai bahasa internasional, bahasa Inggris telah banyak digunakan diseluruh dunia. Dengan menggunakan bahasa Inggris, kita dapat berkomunikasi dengan negara lain. Di Indonesia, bahasa Inggris merupakan bahasa asing dan telah diajarkan secara formal sejak dibangku sekolah dasar hingga tingkat universitas. Namun faktanya adalah bahwa pembelajaran Bahasa Inggris sebagai bahasa asing di Indonesia masih dianggap gagal, sebagaimana dilansir dari pidato pengukuhan guru besar Profesor Bambang Setiyadi di Universitas Lampung pada bulan Nopember 2009 yang lalu. Siswa menghadapi kendala baik menulis maupun berbicara dalam bahasa Inggris. Mereka merasa kesulitan ketika menyampaikan ide,ataupun pendapat. Sehingga pembelajaran bahasa Inggris ditujukan tidak hanya dalam penguasaan aturan grammar, tetapi juga dapat menggunakan bahasa Inggris aktif dengan baik.

Berdasarkan hasil obervasi yang dilaksanakan pada mahasiswa-mahasiswa di AMIK Dian Cipta Cendikia peneliti menemukan bahwa mahasiswa mengalami kesulitan dan takut untuk mengekspresikan pendapat secara lisan. Selain itu teknik pembelajaran yang digunakan oleh dosen masih kurang bervariasi, sehingga pembelajaran menjadi monoton sehingga kurang memotivasi mahasiswa untuk terus belajar berbahasa Inggris. Cohen (1994:30) menyatakan bahwa cara terbaik dalam menilai kemampuan bahasa di kelas bisa dilakukan dengan beberapa pendekatan eklektik, dimana bermacam variasi digunakan. Fachrurrazy (2002:9) menambahkan bahwa teknik adalah kegiatan spesifik yang dimanifestasikan dalam kelas yang selaras konsisten dengan metode. Sehingga teknik akan selaras juga dengan sebuah pendekatan.Beranjak dari fakta dan didukung oleh pendapat tersebut mendorong peneliti untuk berupaya mengatasi masalah dengan menggunakan game. Game sebagai salah satu teknik dalam pembelajaranbisa membantu siswa dalam mendapatkan ide untuk mengkreasikan dan menkontruk kata ke dalam kalimat.

Ketika kita mendengar kata 'game' konotasinya adalah sesuatu yang menyenangkan, dan penuh kegembiraan. Game sejatinya bisa digunakan berbagai kalangan, mulai dari usia kanak - kanak hingga usia dewasa. Ketika bermain game, kita merasa enjoy dan berkompetisi untuk menjadi pemenang dan berhak mendapatkan reward, skor ataupun poin. Hal tersebut membuat pemain tidak merasa lelah. Uberman (1998) mengatakan bahwa game atau permainan menawarkan kepada siswa suasana yang penuh dengan kesenangan dan menenangkan. Setelah 
pembelajaran. Siswa memperoleh kesempatan untuk menggunakan bahasa dengan cara yang santai dan tidak menegangkan. Game juga berpotensi untuk membantu meningkatkan minat siswa untuk terus belajar. Hal ini didukung oleh temuan Trisnadewi dan Lestari (2018) dalam penelitiannya bahwa permainan bahasa membangkitkan minat dan motivasi mahasiswa untuk belajar bahasa Inggris dan berpartisipasi pada setiap kegiatan yang dilakukan di kelas. Dengan demikian game dapat dimanfaatkan untuk membantu proses pembelajaran sehingga tujuan pembelajaran akan dapat tercapai dengan baik.

Ada ratusan game yang bisa digunakan dalam proses belajar mengajar. Secara alamiah, kebanyakan siswa menyukai game dalam dunia mereka.Gibbs dalam Bakhsh (2016) menyatakan bahwa game adalah sebuah aktifitas yang dilakukan dengan cara bekerjasama atau berkompetisi dalam membuat keputusan, mencari sesuatu, yang disusun dalam seperangkat aturan dan prosedur.

Ada banyak cara yang digunakan untuk meningkatkan skill bahasa siswa. Salah satunya adalah Hide a Word. Game ini adalah sebuah game yang membantu siswa untuk aktif dalam berbicara, yang bermanfaat sekaligus menyenangkan bagi siswa (Katie, www.tefllogue.com/inthe-classroom-games-hide-a-word.html). Adapun prosedur pembelajarannya adalah sebagai berikut:

- Guru menyiapkan beberapa lembar potongan kertas berisi kata (topic)

- Guru membagi siswa dalam beberapa grup

- Siswa bekerja sama dalam grup atau individu

- Guru menjelaskan peraturan permainan

- Setiap grup mengirimkan seorang wakilnya untuk mengambil potongan kertas dan berbicara tentang topic berupa beberapa kata kunci sesuai kata yang tertera kertas dalam waktu 1 menit.

- Jika grup bisa menebak kata, grup mendapatkan poin. Tetapi jika tidak dapat menebak, maka tidak mendapatkan poin.

\section{METODE PENELITIAN}

Adapun tujuan penelitian untuk lebih memfokuskan pada pengaruh Game Hide a Word terhadap kemampuan berbicara bahasa Inggris mahasiswa. Penelitian ini dilaksanakan di AMIK Dian Cipta Cendikia. Subjeknya adalah mahasiswa kelas D3MI 2 semester ganjil 2021/2022 terdiri dari 38 siswa, 16 laki - laki dan 22 perempuan. Teknik sampling yang digunakan adalah cluster random sampling. Data dikumpulkan melalui test lisan untuk mengetahui kemampuan berbicara siswa yang meliputi beberapa komponen bahasa, antara lain; accuracy dan fluency. Setelah data diperoleh, selanjutnya data akan dianalisis melalui uji ttest.

\section{HASIL DAN PEMBAHASAN}

Hasil

Pre-test dan post test dilakukan berdasarkan komponen kemampuan berbicara yakni accuracy dan fluency. Datanya adalah sebagai berikut:

Tabel 1. Frekuensi dan rerata prosentase kemampuan berbicara pada komponen keakuratan (accuracy)

\begin{tabular}{|l|l|l|c|c|c|c|}
\hline No & Skor & Kategori & \multicolumn{2}{|c|}{ Pre-test } & \multicolumn{2}{|c|}{ Post test } \\
\cline { 4 - 7 } & & $\begin{array}{l}\text { Frekuen } \\
\text { si }\end{array}$ & Prosentase & $\begin{array}{l}\text { Frekuen } \\
\text { si }\end{array}$ & Prosentase \\
\hline 1 & $9.6-10$ & Excellent & - & 0 & - & 0 \\
\hline 2 & $\begin{array}{l}8.6- \\
9.5\end{array}$ & Very good & - & 0 & - & 0 \\
\hline 3 & $\begin{array}{l}7.6- \\
8.5\end{array}$ & Good & 3 & $7.9 \%$ & 11 & $29 \%$ \\
\hline
\end{tabular}


STRATEGY : Jurnal Inovasi Strategi dan Model Pembelajaran

Vol 1. No 2. Oktober Tahun 2021 e-ISSN : 2798-5466 P-ISSN : 2798-5725

\begin{tabular}{|l|l|l|c|c|c|c|}
\hline 4 & $\begin{array}{l}6.6- \\
7.5\end{array}$ & $\begin{array}{l}\text { Fairly } \\
\text { good }\end{array}$ & 11 & $29 \%$ & 14 & $37 \%$ \\
\hline 5 & $\begin{array}{l}5.6- \\
6.5\end{array}$ & Poor & 13 & $34 \%$ & 11 & $29 \%$ \\
\hline 6 & $\begin{array}{l}0.0- \\
5.5\end{array}$ & Very poor & 11 & $29 \%$ & 2 & $5.3 \%$ \\
\hline & Total & & & $100 \%$ & 38 & $100 \%$ \\
\hline
\end{tabular}

Data pada table diatas memunjukkan bahwa pada pre-test, ada 11 mahasiswa atau $29 \%$ kategori very poor, 13 siswa atau $34 \%$ kategori poor, 11 mahasiswa atau $29 \%$ kategori fairly good dan 3 mahasiswa atau 7,9\% kategori good.

Dan table tersebut memperlihatkan bahwa hasil test uji post-test kemampuan berbicara pada komponen akurasi, ada 2 mahasiswa atau 5,3\% kategori very poor, 11 mahasiswa atau 29 $\%$ kategori poor, 14 mahasiswa atau $37 \%$ kategori fairly good dan 11 mahasiswa atau $29 \%$ kategori good.

Tabel 2. Frekuensi dan rata-rata prosentase kemampuan berbicara pada komponen kefasihan (fluency)

\begin{tabular}{|l|l|l|c|c|c|c|}
\hline No & \multirow{2}{*}{ Skor } & Kategori & \multicolumn{2}{|c|}{ Pre-test } & \multicolumn{2}{|c|}{ Post test } \\
\cline { 3 - 7 } & & & $\begin{array}{l}\text { Frekuen } \\
\text { si }\end{array}$ & $\begin{array}{l}\text { Prosentas } \\
\text { e }\end{array}$ & $\begin{array}{l}\text { Frekuen } \\
\text { si }\end{array}$ & Prosentase \\
\hline 1 & $9.6-10$ & Excellent & - & 0 & - & 0 \\
\hline 2 & $\begin{array}{l}8.6- \\
9.5\end{array}$ & Very good & - & 0 & - & 0 \\
\hline 3 & $\begin{array}{l}7.6- \\
8.5\end{array}$ & Good & - & 0 & - & 0 \\
\hline 4 & $\begin{array}{l}6.6- \\
7.5\end{array}$ & $\begin{array}{l}\text { Fairly } \\
\text { good }\end{array}$ & - & 0 & 16 & $42 \%$ \\
\hline 5 & $\begin{array}{l}5.6- \\
6.5\end{array}$ & Poor & 12 & $32 \%$ & 15 & $39 \%$ \\
\hline 6 & $\begin{array}{l}0.0- \\
5.5\end{array}$ & Very poor & 26 & $68 \%$ & 7 & $19 \%$ \\
\hline & Total & & 38 & $100 \%$ & 38 & $100 \%$ \\
\hline
\end{tabular}

Data pada table diatas menunjukkan bahwa pada pre-test, ada 26 mahasiswa atau $68 \%$ kategori very poor, dan 12 mahasiswa atau $32 \%$ kategori poor.

Dan table tersebut juga memperlihatkan bahwa hasil test uji post-test kemampuan berbicara pada komponen fluency, ada 7 siswa atau $19 \%$ kategori very poor, 15 mahasiswa atau $39 \%$ kategori poor, dan 16 mahasiswa atau $42 \%$ kategori fairly good. 


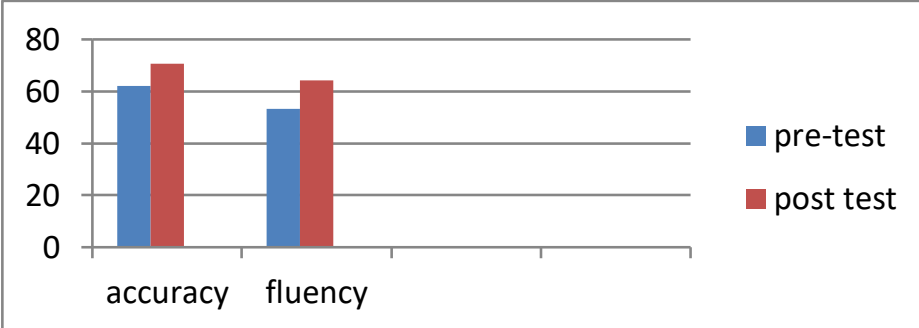

\section{Gambar 1. Grafik Nilai Rata - Rata Pretest dan Post Test untuk Komponen Accuracy dan Fluency}

Berdasarkan grafik, nilai rata-rata pretest dan post test menunjukkan bahwa rat-rata nilai prestest dan post test baik pada komponen accuracy dan fluency mengalami kenaikan. Hasil ini menunjukkan bahwa kedua komponen mengalami progress yang baik setelah pembelajaran keterampilan berbicara bahasa Inggris melalui teknik Game Hide a Word. Pretest dan post test ini sangat penting untuk diukur, tujuannya ialah untuk mengetahui seberapa baik perkembangan dan keterampilan siswa dalam proses pembelajaran, khususnya dalam pembelajaran keterampilan berbicara bahasa Inggris.

\section{Uji Hipotesa}

Untuk mengetahui level signifikansi pretest dan post test, peneliti menggunakan t-test analisis dengan level signifikansi $(p)=0,05$ dengan degree of freedom $(\mathrm{df})=\mathrm{N}-1(38-1=37)$, dimana $\mathrm{N}=$ jumlah subyek (38 mahasiswa) kemudian dengan nilai t-tabel sebesar 1.729. Analisis independent sample digunakan.

Berikut adalah hasilnya :

Table 3. Test Peningkatan Kemampuan Berbicara Siswa

\begin{tabular}{|l|c|c|}
\hline componen & t-test value & t-table value \\
\hline Accuracy & 5.39 & 1.729 \\
\hline Fluency & 7.35 & 1.729 \\
\hline Speaking ability & 6.35 & 1.729 \\
\hline
\end{tabular}

Tabel diatas menunjukkan bahwa nilai t-test untuk accuracy lebih besar daripada t-table $(5,39>1,729)$. Ini berarti bahwa ada perbedaan antara kemampuan accuracy mahasiswa sebelum dan sesudah pembelajaran menggunakan Game Hide a Word. Tabel tersebut juga memperlihatkan bahwa t-test value untuk fluency lebih besar dari pada t-table $(7,35>1,729)$. Hal ini berarti bahwa ada perbedaan yang signifikan kemampuan fluency mahasiswa sebelum dan sesudah pembelajaran menggunakan Game Hide a Word. Dan dibuktikan bahwa H0 ditolak dan H1 diterima. Yang berarti adalah ada perbedaan signifikan antara kemampuan berbicara mahasiswa sebelum dan sesudah pembelajaran menggunakan Game Hide a Word, atau bisa dikatakan bahwa penggunaan Game Hide a Word efektif untuk meningkatkan kemampuan berbicara mahasiswa.

\section{Pembahasan}

Berdasarkan data yang diperoleh dalam penelitian ini, ditemukan bahwa hasil uji komponen accuracy pada mahasiswa sebelum perlakuan diberikan ada 26 mahasiswa atau 68 $\%$ termasuk kategori very poor dan 12 mahasiswa atau $32 \%$ termasuk kategori poor. Sedangkan setelah perlakuan diberikan ada 7 mahasiswa atau $19 \%$ kategori very poor dan 15 kategori poor dan 16 mahasiswa tau $42 \%$ kategori fairly poor. Dengan demikian jumlah frekuensi mahasiswa dengan kategori very poor mengalami penurunan, sedangkan jumlah frekuensi mahasiswa dengan kategori fairly good mengalami peningkatan. Dan hasil uji hipotesa membuktikan bahwa ada perbedaan signifikan antara kemampuan berbicara mahasiswa sebelum dan sesudah 
pembelajaran menggunakan game hide a word, atau bisa dikatakan bahwa penggunaan Game Hide a Word eefektif untuk meningkatkan kemampuan berbicara mahasiswa.

Hal ini didukung oleh fakta yang ditemukan pada penelitian yang dilakukan oleh Wulandari (2020) dengan judul Penggunaan Kartu Game Information Gap untuk Meningkatkan Hasil Belajar Bahasa Inggris. Penelitian tersebut menemukan bahwa tingkat pemahaman siswa tentang menyatakan dan menanyakan sifat orang, binatang dan benda setelah pembelajaran menggunakan Kartu Game Information Gap dapat meningkat dengan baik. Hal ini mengisyaratkan bahwa pembelajaran dengan media game atau permainan sangat membantu siswa dalam memperbaiki kualitas keterampilan dan komponen bahasa yang sedang mereka pelajari.

Lebih lanjut seperti yang diungkapkan oleh Uberman (1998) bahwa game atau permainan menawarkan kepada siswa suasana yang penuh dengan kesenangan dan menenangkan. Dengan pendapat ini dapat dipahami bahwa pembelajaran yang dilakukan dengan suasana menyenangkan dan menenangkan berpotensi untuk memotivasi siswa untuk belajar, sehingga tujuan pembelajaran yang sudah direncanakan akan dapat tercapai.

Hanifah (2016) dalam penelitiannya berjudul Penerapan Model PAIKEM dengan Menggunakan Media Permainan Bahasa dalam Pembelajaran Bahasa Arab, menyimpulkan bahwa pembelajaran bahasa arab akan lebih efektif jika dilakukan dengan menggunakan media permainan bahasa. Hal ini jelas sangat mungkin berlaku untuk pembelajaran bahasa pada umumnya, karena permainan yang sedianya dilakukan guna menambah aktifitas bergembira semata, namun juga dapat menjadi wahana untuk membantu siswa dalam berlatih dan mengeksplor keterampilan bahasa yang sedang dipelajarinya.

\section{KESIMPULAN}

Berdasarkan hasil analisis data yang diperoleh dalam penelitian ini, maka dapat disimpulkan bahwa penggunaan Game Hide a Word dapat meningkatkan kemampuan berbicara bahasa Inggris mahasiswa dalam hal ini komponen accuracy dan fluency. Hal ini dibuktikan dengan rata-rata prosentase pretest komponen accuracy adalah $63 \%$ dengan kategori poor dan very poor, dan setelah diberikan perlakuan, hasil post test menunjukkan kenaikan dengan rata - rata prosentase $13 \%$ dengan kategori poor dan very poor. Hal ini menunjukkan membaiknya kemampuan accuracy mahasiswa. Selain itu rata-rata pre test kemampuan fluency ada $100 \%$ dalam kategori poor dan very poor, dan setelah diberikan perlakuan, hasil post test memperlihatkan adanya perbaikan kemampuan fluency dengan prosentase $58 \%$ dalam kategori poor dan very poor. Dari kesimpulan hasil penelitian yang diperoleh, peneliti merekomendasikan kepada peneliti yang akan datang agar lebih mengeksplor teknik Game Hide a Word ini untuk memperbaiki keterampilan produktif lain, seperti keterampilan menulis maupun komponen bahasa yang lain seperti penguasaan kosa kata, pengucapan dan tata bahasa.

\section{DAFTAR PUSTAKA}

Bakakhsh, Sahar Ameer. (2016). Using Game as a Tool in teaching Vocabulary to Young Learners. English Language Teaching. Vol. 9, No. 7; 2016 published by Canadian of Science and Education. http://dx.doi.org/10.5539/elt.v9n7p120

Cohen, A.D. (1994). Assesing Languege Ability in the Classroom. USA: Hainle \& Hainle.

Fachrurrazy. (2002). Teaching English as Foreign Language. Malang: The State University of Malang.

Hanifah, Umi. (2016). Penerapan Model PAIKEM dengan Menggunakan Media Permainan Bahasa dalam Pembelajaran Bahasa Arab. Jurnal Ilmu Tarbiyah "At Tajdid." Vol. 5 No. 2;

Katie. TEFL Classroom Games. Hide a Word. www.tefllogue.com/in-the-classroom-gameshide -a-word.html [Online: 25 Agustus 2014]

Sudjana. (2005). Metode Statistika. Bandung: Tarsito. 
Trisnadewi, Komang dan Eka Ayu Purnama Lestari. (2018). Pengaruh Language Game terhadap Kemampuan Berbicara Bahasa Inggris. Jurnal Bahasa dan Budaya Kulturistik. Vol 2 No.1, 66-78. https://ejournal.warmadewa.ac.id/idnex.php/kulturistik

Uberman, A. (1998). The Use of Games: For Vocabulary Presentation and Revision. English Teaching Forum 36 (1): 20 http://exchanges.state.gov/forum/ vols/vol36/no1/p20.html [Online: 25 Agustus 2014]

Wulandari, Winda.(2020). Penggunaan Kartu Game Information Gap untuk Meningkatkan Hasil Belajar Bahasa Inggris. Jurnal Pendidikan pemuda Vo. 2 No. 1. http://jurnal.stkipm-pagaralam.ac.id 